Research Paper

\title{
Relationship between Oral Anaerobic Bacteria and Otitis Media with Eifiusion
}

\author{
Nursen Topcuoglu四, Fahriye Keskin ${ }^{1}$, Sevgi Ciftci ${ }^{1}$, Ceki Paltura², Mehmet Kulekci², Duran Ustek ${ }^{3}$, Guven \\ Kulekci ${ }^{1}$
}

1. Oral Microbiology Laboratory, Istanbul University Faculty of Dentistry, Istanbul, Turkey;

2. Department of Otorhinolaryngology, Head and Neck Surgery, Taksim Training and Research Hospital, Istanbul, Turkey;

3. Department of Genetics, Institute for Experimental Medicine, Istanbul Faculty of Medicine, Istanbul, Turkey.

Corresponding author: Tel: +902124142595; Fax: +902125312230, E-mail address: nursentopcuoglu@yahoo.com (N. Topuoglu).

(C) Ivyspring International Publisher. This is an open-access article distributed under the terms of the Creative Commons License (http://creativecommons.org/ licenses/by-nc-nd/3.0/). Reproduction is permitted for personal, noncommercial use, provided that the article is in whole, unmodified, and properly cited.

Received: 2012.03.19; Accepted: 2012.05.03; Published: 2012.05.07

\begin{abstract}
Objective: In this study hypothesing the translocation of oral bacteria from oropharynx into the middle ear cavity may be involved in the pathogenesis of otitis media with effusion (OME), we aimed to investigate the presence and similarity of Fusobacterium nucleatum and Treponema denticola in saliva, nasopharyngeal secretion and the middle ear effusion samples from the children with OME.

Methods: Totally 20 children with OME undergoing myringotomy and ventilation tube placement were attended. Stimulated saliva samples were collected after otorhinolaryngological and oral examinations were done. The middle ear effusion and nasopharyngeal secretions were collected during the operations. The presence of $F$. nucleatum and $T$. denticola were detected using I6SrRNA-based PCR. The clonal similarities of the bacteria were detected in the samples which the same bacteria had been detected in each samples of the same child. After DNA sequencing, clonal similarity was determined by I6SrRNA gene clone library analysis. The sequences from each clone were compared with similar sequences of reference organisms by FASTA search.

Results: T. denticola was detected only in four $(20 \%)$ saliva and in one $(5 \%)$ nasopharyngeal sample. F. nucleatum was detected in II (55\%) saliva, eight (40\%) nasopharyngeal and six (30\%) middle ear effusion samples. Sequences from F.nucleatum clones derived from three different anatomic sites within patients were similar in 33\% of OME patients, indicating their genetic relatedness.

Conclusions: Bacteria involved in this process most likely originate from the oropharynx since they show a close genetic relatedness with their oropharyngeal counterparts.
\end{abstract}

Key words: Middle ear effusion, saliva, Fusobacterium nucleatum, sequence analysis.

\section{Introduction}

Otitis media with effusion (OME) is an inflammation of the middle ear, accompanied by the accumulation of fluid in the middle ear cleft without the symptoms and signs of acute inflammation (1). It is a common childhood disease which can lead to significant hearing loss in pediatric patients, resulting in developmental problems in speech, language, and the acquisition of social skills $(2,3)$. Once a decision has 
been taken to offer surgical intervention for OME in children, the insertion of ventilation tubes is recommended.

Streptococcus pneumoniae, Haemophilus influenzae, and Moraxella catarrhalis are isolated from approximately $25 \%$ of children with OME, but PCR-based methods have demonstrated sequence specific DNA and RNA for these pathogens in nearly $80 \%$ of cases (4-7). In our previous study, bacterial DNA were determined from $42 \%$ of the middle ear effusion (MEE) samples, which, $37 \%$ of them were positive for Fusobacterium nucleatum and one of them was positive for both F. nucleatum and Treponema denticola (8). T. denticola was found to be the second most common periodontal pathogen among the periodontally healthy children (9).

OME has been suggested to be a continuum of acute otitis media (AOM) (10). It was speculated that environmental/ecological changes in the nasopharynx during AOM episodes may favor the growth of anaerobes, which can be recovered frequently during infection in children under two years old, but not during health (11). The main anaerobes that are found in nasopharyngeal aspirates collected during AOM are F. nucleatum and Prevotella melaninogenica (12). These species are also among the principal anaerobic bacteria that are found in chronic OME $(13,14,15)$.

Saliva contains a variety of bacteria from different oral sites; therefore it is representative for all oral microflora (16). It seems to be a transmission vehicle for translocation of oral bacteria between the oral cavity and nasopharynx. Clonal similarity of the $F$. nucleatum strains between nasopharynx and saliva of the children with AOM has been shown previously (17). It is well acknowledged that microorganisms from the nasopharynx can reach the middle ear cavity via the eustachian tube and cause middle ear infection $(18,19)$.

Based on the published data, we hypothesize that the translocation of oral bacteria from oropharynx into the middle ear cavity may be involved in the pathogenesis of OME. In this study, we aimed to investigate the presence and clonal similarity of $F$. nucleatum and T. denticola in saliva, nasopharyngeal and middle ear effusion samples from the children with OME.

\section{Materials and Methods}

\section{Study population}

A total of 20 children with OME aged 4-11 years (mean age $7.8 \pm 1.9$ years) undergoing myringotomy and tube placement at the Department of Otorhinolaryngology, Head and Neck Surgery at Taksim
Training and Research Hospital, Istanbul, Turkey. At the time of study enrollment, parents provided their informed consent for all infants which was approved by the Local Ethics Committee of the Istanbul University Faculty of Medicine (2008/930).

After otorhinolaryngological examination, oral hygiene and gingival status were assessed using the Simplified Oral hygiene index (20) and gingival index (21), respectively. Paraffin stimulated saliva samples were collected immediately after clinical examination. Middle ear effusion and nasopharyngeal secretions were obtained during anesthesia for insertion of ventilation tubes (8). All the samples were stored at $-80^{\circ} \mathrm{C}$ until use.

\section{PCR assay}

Saliva samples were diluted 1:2 and washed four times. MEE samples were lyzed at $56^{\circ} \mathrm{C}$ for $3 \mathrm{~h}$ after $20 \mu 1$ proteinase $\mathrm{K}$ addition. DNA was isolated from $F$. nucleatum ATCC 25586, T.denticola 35405 and the clinical samples, by using a MagNA Pure automated DNA extraction platform (Roche Diagnostics) as recommended by the manufacturer.

16SrRNA primers (F. nucleatum Forward 5'-CGC AGA AGG TGA AAG TCC TGT AT-3', Reverse 5'-TGG TCC TCA CTG ATT CAC ACA GA-3' and T. denticola Forward 5' - TAA TAC CGA ATG TGC TCA TTT ACA T-3', Reverse 5'-CTG CCA TAT CTC TAT GTC ATT GCT CTT-3') were used to amplify the 264-bp-long region of $F$. nucleatum and 862-bp-long region of T. denticola. $50 \mathrm{ng}$ DNA was added into the PCR mixture containing $10 \mathrm{pmol}$ of each primer, $1.5 \mathrm{mM} \mathrm{MgCl} 2,50 \mu \mathrm{M}$ of deoxyribonucleotide triphosphate (Pharmacia LKV), $0.15 \mathrm{U}$ of Taq polymerase and $5 \mu$ of buffer 10x.

The PCR profile for F. nucleatum included an initial denaturation at $95^{\circ} \mathrm{C}$ for $3 \mathrm{~min}$ followed by $30 \mathrm{cy}-$ cles consisting of $94^{\circ} \mathrm{C}$ for $30 \mathrm{~s}, 66^{\circ} \mathrm{C}$ for $30 \mathrm{~s}, 72^{\circ} \mathrm{C}$ for $30 \mathrm{~s}$ and a final extension at $72^{\circ} \mathrm{C}$ for $5 \mathrm{~min}$. The PCR profile for $T$. denticola included an initial denaturation at $92^{\circ} \mathrm{C}$ for $2 \mathrm{~min}$ followed by 36 cycles consisting of $95^{\circ} \mathrm{C}$ for $30 \mathrm{~s}, 58^{\circ} \mathrm{C}$ for $120 \mathrm{~s}, 72^{\circ} \mathrm{C}$ for $60 \mathrm{~s}$ and a final extension at $72^{\circ} \mathrm{C}$ for $5 \mathrm{~min}$.

Following amplification, $10 \mu \mathrm{l}$ of PCR products were analyzed by electrophoresis on agarose gels. Gels were stained with $0.5 \mu \mathrm{g}$ ethidium bromide $\mathrm{ml}^{-1}$ and visualized by ultraviolet light illumination.

\section{Sequence analysis}

Sequences were assembled after sample purification using a purification kit (Roche Diagnostics). DNA were directly sequenced in Beckman Coulter CEQ 8000 Genetic Analysis System using Beckman Coulter DTCS Quick Start kit. 
Sequence comparisons were determined by 16SrRNA gene clone library analysis. The sequences from each sample were compared with similar sequences of reference organisms by FASTA search. Clinical sequences were required to be $>98 \%$ similar to reference organisms in the database for 16S rRNA gene sequence similarity (22).

\section{Statistical analysis}

The results of the conventional PCR were described using absolute and percentage frequency and the clinical conditions were compared with Fischer's Exact test and student-t test with a significance level of 0.05 .

\section{Results}

A total of 20 children (4-11 years old, mean age 8 years; 11 male and 9 female) were clinically examined and sampled for microbiological analysis. Sixteen subjects $(80 \%)$ were in mixed dentition and 12 subjects $(60 \%)$ had been used antibiotic within last 3 months. Mean oral hygiene and gingival index scores were $1.36 \pm 0.29$ and $0.29 \pm 0.36$, respectively.

Table 1 shows the prevalence and distribution of target bacterial species in clinical samples from 20 children. F. nucleatum was detected from 11 (55\%), eight $(40 \%)$ and six $(30 \%)$ salivary, nasopharyngeal and middle ear effusion samples of the 20 subjects, respectively. F. nucleatum was detected from six $(30 \%)$ of the children's each three samples (Patient no: 1, 4, 7, 11, 12 and 13) and two (10\%) of the children's saliva and nasopharyngeal samples (Patient no: 3 and 9). The clinical conditions of the children who revealed or not revealed F.nucleatum in their MEE samples are shown in Table 2. The clinical conditions were not statistically different $(P>0.05)$.

$F$. nucleatum was assessed in eight cases in at least two samples. The same clonal frames were detected in each sample of two $(10 \%)$ children (Patient no: 4 and 13), while different frames were detected from middle ear effusion samples of the two children (Patient no: 1 and 11) and from all samples of one child (Patient no: 7). A mixed population was determined from one child's nasopharyngeal sample, whose other two samples showed different clonal frames (Patient no: 12). Thus, the rate of genetic relatedness between $F$. nucleatum clones per patient which F. nucleatum were detected from three locations (middle ear effusion, nasopharyngeal secretion and saliva) indicated a clonal origin is 33\% (Table 3).

The children with double F. nucleatum positive samples (Patient no: 3 and 9) revealed the same clonal frames in their each sample. Thus, a total of six $(30 \%)$ children (Patient no: 1,3,4,9,11 and13) was found to carry the same F. nucleatum clonal frames in their nasopharynx and oral microflora. The rate of genetic relatedness between $F$. nucleatum clones per patient which F. nucleatum were detected from two locations (nasopharyngeal secretion and saliva) indicated a clonal origin is $75 \%$ (Table 3 ).

T. denticola was detected from four $(20 \%)$ saliva samples and one (5\%) nasopharyngeal secretion sample, while it was not detected in any middle ear effusion sample (Table 1). Sequence similarity could not be performed because of the fact that, none of the children harbored $T$. denticola in their each samples.

Table I. Number and percentage of OME patient with positive samples distributed over respective locations.

\begin{tabular}{lllll}
\hline & \multicolumn{2}{l}{ F.nucleatum } & \multicolumn{2}{l}{ T.denticola } \\
\hline Location & $f$ & $\%$ & $f$ & $\%$ \\
\hline Saliva+NS+MEE & 6 & 30 & 0 & 0 \\
Only Saliva+NS & 2 & 10 & 0 & 0 \\
Only Saliva & 3 & 15 & 4 & 20 \\
Only NS & 0 & 0 & 1 & 5 \\
Only MEE & 0 & 0 & 0 & 0 \\
TOTAL & 11 & 55 & 5 & 25 \\
\hline
\end{tabular}

$f$, Frequency; NS, nasopharyngeal secretion; MEE, middle ear effusion.

Table 2. Clinical conditions of the children according to presence of F.nucleatum in their MEE samples.

\begin{tabular}{|c|c|c|c|c|c|c|}
\hline $\begin{array}{l}\text { F.nucletum positive in } \\
\text { MEE samples }\end{array}$ & $\mathrm{n}$ & Mixed dentition & Age & Plaque index & Gingival index & Antibiotic usage \\
\hline Yes & 6 & $5(83 \%)$ & $7.7 \pm 1.9$ & $1,36 \pm 0,75$ & $0,11 \pm 0,20$ & $5(83 \%)$ \\
\hline No & 14 & $11(79 \%)$ & $7.9 \pm 1.9$ & $1,37 \pm 0,57$ & $0,37 \pm 0,39$ & $7(50 \%)$ \\
\hline Total & 20 & $16(80 \%)$ & $7.8 \pm 2$ & $1,36 \pm 0,29$ & $0,29 \pm 0,36$ & $12(60 \%)$ \\
\hline
\end{tabular}


Table 3. The clonal similarities of the Fusobacterium nucleatum obtained from the samples with reference organisms.

\begin{tabular}{|c|c|c|c|c|c|}
\hline \multirow{2}{*}{$\begin{array}{l}\mathrm{Pa}- \\
\text { tient } \\
\text { No }\end{array}$} & \multirow[t]{2}{*}{ Sample } & \multirow{2}{*}{$\begin{array}{l}\text { Se- } \\
\text { quence } \\
\text { No }\end{array}$} & \multicolumn{3}{|c|}{ F.nucleatum reference strains } \\
\hline & & & $\begin{array}{l}\text { ATCC } \\
49256\end{array}$ & $\begin{array}{l}\text { ATCC } \\
25586\end{array}$ & $\begin{array}{l}\text { ATCC } \\
33693\end{array}$ \\
\hline \multicolumn{6}{|c|}{ Triple samples } \\
\hline \multirow[t]{3}{*}{1} & MEE & 801 & & 100 & \\
\hline & Saliva & 807 & & & 100 \\
\hline & NS & 813 & & & 100 \\
\hline \multirow[t]{3}{*}{4} & MEE & 802 & & 100 & \\
\hline & Saliva & 808 & & 100 & \\
\hline & NS & 814 & & 100 & \\
\hline \multirow[t]{3}{*}{7} & MEE & 803 & 100 & & \\
\hline & Saliva & 809 & & & 100 \\
\hline & NS & 815 & & 100 & \\
\hline \multirow[t]{3}{*}{11} & MEE & 804 & & 100 & \\
\hline & Saliva & 810 & & & 100 \\
\hline & NS & 816 & & & 100 \\
\hline \multirow[t]{3}{*}{12} & MEE & 805 & & 100 & \\
\hline & Saliva & 811 & & & 100 \\
\hline & NS & 817 & & Mixed & \\
\hline \multirow[t]{3}{*}{13} & MEE & 806 & & 100 & \\
\hline & Saliva & 812 & & 100 & \\
\hline & NS & 818 & & 100 & \\
\hline \multicolumn{6}{|c|}{ Double samples } \\
\hline \multirow[t]{2}{*}{3} & Saliva & 819 & & 100 & \\
\hline & NS & 821 & & 100 & \\
\hline \multirow[t]{2}{*}{9} & Saliva & 820 & & & 100 \\
\hline & NS & 822 & & & 100 \\
\hline
\end{tabular}

NS: nasopharyngeal secretion; MEE: middle ear effusion.

\section{Discussions}

The pathogenesis of OME appears to be multifactorial, including immature anatomy, initiating viral infections that induce eustachian tube dysfunction, retrograde movement of bacteria from the oropharynx into the middle ear cavity, and host physiological factors (5). Eustachian tube dysfunction may create reduced oxygen pressure in the middle ear cavity and therefore this environmental change may favor the growth of anaerobes.

Knowledge about anaerobic bacteria in the pathogenesis of OME is very limited and mostly depends on cultural studies $(8,23,24)$. The anaerobes involved in middle ear infections originate from the oropharyngeal cavity, where they constitute normal flora, outnumbering the aerobic and facultative bacteria in a 10-100 to 1 ratio (13).
Anaerobes contribute to the severity and chronicity of infections that occur in and around the oral cavity. F. nucleatum is a commensal oral bacterium on various oral mucosal surfaces and in dental plaque. $F$. nucleatum can be isolated from oral mucosal surfaces of the edentulous infants. The frequency of isolation rises with age, probably due to the better living environment that is created with the eruption of teeth (25). In our study, five of six F. nucleatum positive children in MEE were in mixed dentition.

Fusobacterium nucleatum is considered to be a key species in building the community structure in dental biofilm and on various oral mucosal surfaces. Although strictly anaerobic, it is assumed that F. nucleatum is capable of surviving in aerobic environments because of its coaggregation with oxygen-consuming bacteria (26). In our study, while the salivary presence rate was $55 \%$, mean oral hygiene and gingival levels were similar between the children with and without $F$. nucleatum in MEE samples.

F. nucleatum is frequently found in middle ear effusions from children with OME $(8,14)$. Sequences from F. nucleatum clones derived from three different anatomic sites were similar within two of the six (33\%) OME patients. This result indicates the genetic relatedness between oropharyngeal flora and middle ear effusion. The source of the bacteria is important, because many F. nucleatum strains present in the oral cavity of young children produce $\beta$-lactamases (27). Since, $\beta$-lactam antibiotics are commonly used for upper respiratory tract infections, F. nucleatum strains, which translocate to middle ear cavity, can persist to colonize even the antibiotic therapy. In our study, five of the six $(83 \%)$ of the children with F. nucleatum in MEE samples had been used antibiotics within the last 3 months, while totally 12 (60\%) of the children used antibiotics. As it is not statistically significant, in these circumstances, it may be significant if we increase the numbers of the samples.

Clonal similarities of F. nucleatum isolates collected from the nasopharynx and saliva of the infants with AOM has been shown using arbitrarily primed PCR (17). It was also reported that environmental/ecological changes in the nasopharynx during $\mathrm{AOM}$ was favor the growth of anaerobes (12). In our study, similar clonal frames were found among salivary and nasopharyngeal samples in six of the eight children whose nasopharyngeal secretion samples were F. nucleatum positive. The present observation indicates that the source of nasopharyngeal anaerobes may be the oral cavity and the saliva may be their transmission vehicle.

F. nucleatum is a heterogeneous species with numerous genotypic profiles and high heterogeneity 
of serovars and ribotypes have been found within individuals (28-30). The high intra-individual clonal heterogeneity and frequent turnover of clones among oral F. nucleatum populations was claimed to allow the species to escape the host immune response, which is targeted against pathogens, and persist to colonize the oral cavity. In this study, intra-individual clonal heterogeneity was detected in each sample of two children. Thus, the translocation of oral bacteria from oropharynx into the middle ear cavity may be involved in the pathogenesis of OME. Nasopharyngeal microflora may be considered to be the source of other regions, because, in this study, different clones was observed in one child's saliva and MEE sample, while a mixed population was observed in his nasopharynx.

In our previous study, which F. nucleatum had not been searched, $T$. denticola $(32 \%)$ was the second most prevalent periodontal bacteria following Prevotella nigrescens $(80 \%)$ in 41 periodontally healthy Turkish children in mixed dentition (9). As our study population was similar to that study, we thought it was important to detect $T$. denticola which was also previously detected in MEE samples (8). In our current study, $T$. denticola was detected from only four (20\%) saliva samples and one $(5 \%)$ nasopharyngeal secretion sample, while it was not detected in any middle ear effusion sample. The detection rates could be higher by using a quantitative real-time PCR assay, which is more sensitive, but in this study, we aimed to detect a sequence-based similarity which a conventional PCR had to be used.

\section{Conclusions}

F. nucleatum in middle ear effusions of OME patients most likely originate from the oropharynx, since they show close genetic relatedness to their oropharyngeal counterparts. With the limitations of this study, it can be concluded that oral bacterial species could gain entry through retrograde movement from the oropharynx into the middle ear cavity and may also play a role in the aetiopathogenesis of OME. The similarities for other oral bacteria can be shown after further detection the microbial profiles of the MEE samples using metagenomic analysis.

\section{Acknowledgements}

This study was supported by the Research Fund of Istanbul University (Project no. 2358 and 15216).

\section{Abbreviations}

OME: otitis media with effusion; AOM: acute otitis media; MEE: middle ear effusion; NS: nasopharyngeal secretion.

\section{Competing Interests}

The authors have declared that no competing interest exists.

\section{References}

1. [Internet] SIGN (Scottish Intercollegiate Guidelines Network). Diagnosis and management of childhood otitis media in primary care. Guideline No:66 February, 2003. http://www.sign.ac.uk/pdf/sign66.pdf

2. Bluestone CD, Klein JO. Otitis Media in Infants and Children. Philadelphia: WB Saunders Company; 1988.

3. Bennett KE, Haggard MP, Silva PA, Stewart IA. Behaviour and developmental effects of otitis media with effusion into the teens. Arch Dis Child. 2001; 85:91-95.

4. Hotomi M, Tabata T, Kakiuchi H, Kunimoto M. Detection of Haemophilus influenzae in middle ear of otitis media with effusion by polymerase chain reaction. Int J Pediatr Otorhinolaryngol. 1993;27:119-126.

5. Post JC, Preston RA, Aul JJ, Larkins-Pettigrew M, Rydquist-White J, Anderson KW, et al. Molecular analysis of bacterial pathogens in otitis media with effusion. JAMA. 1995;273:1598-1604.

6. Rayner MG, Zhang Y, Gorry MC, Chen Y, Post JC, Ehrlich GD. Evidence of bacterial metabolic activity in culture-negative otitis media with effusion. JAMA. 1998;279:296-299.

7. Pereira M.B, Pereira MR, Cantarelli V, Costa SS. Prevalence of bacteria in children with otitis media with effusion. J Pediatr (Rio J). 2004;80:41-48.

8. Külekci G, Ciftci S, Keskin F, Kilic AO, Türkoglu S, Badur S, et al. PCR analysis of Actinobacillus actinomycetemcomitans, Porphyromonas gingivalis, Treponema denticola and Fusobacterium nucleatum in middle ear effusion. Anaerobe. 2001;7:241-246.

9. Külekci G, Leblebicioglu B, Keskin F, Ciftci S, Badur S. Salivary detection of periodontopathic bacteria in periodontally healthy children. Anaerobe. 2008;14:49-54.

10. Giebink GS. Otitis media update: pathogenesis and treatment. Ann Otol Rhinol Laryngol. 1992;155:21-23.

11. Könönen E, Syrjanen R, Takala A, Jousimies-Somer H. Nasopharyngeal carriage of anaerobes during health and acute otitis media by two years of age. Diagn Microbiol Infect Dis. 2003;46:167-172.

12. Könönen E, Kanervo A, Bryk A, Takala A, Syrjanen R, Jousimies-Somer $\mathrm{H}$. Anaerobes in the nasopharynx during acute otitis media episodes in infancy. Anaerobe. 1999; 5:237-239.

13. Brook I, Frazier EH. Microbial dynamics of persistent purulent otitis media in children. J Pediatr. 1996;128:237-240.

14. Brook I, Yocum P, Shah K. Aerobic and anaerobic bacteriology of concurrent chronic otitis media with effusion and chronic sinusitis in children. Arch Otolaryngol Head Neck Surg. 2000;126:174-176.

15. Brook I, Yocum P, Shah K, Feldman B, Epstein S. Aerobic and anaerobic bacteriologic features of serous otitis media in children. Am J Otolaryngol. 1983;4:389-392.

16. Kaufman E, Lamster IB. Analysis of saliva for periodontal diagnosis - a review. J Clin Periodontol. 2000;27:453-465.

17. Haraldsson G, Holbrook WP, Könönen E. Clonal similarity of salivary and nasopharyngeal Fusobacterium nucleatum in infants with acute otitis media experience. J Med Microbiol. 2004;53:161-165.

18. Ueyama T, Kurono Y, Shrabe K, Takeshita M, Magi G. High incidence of Haemophilus influenzae in nasopharyngeal secretions and middle ear effusions as detected by PCR. J Clin Microbiol. 1995;33:1835-1838.

19. Faden H, Duffy L, Wasielewski R, Wolf J, Krystofik D, Tung Y, Tonawanda/ Williamsville Pediatrics. Relationship between nasopharyngeal colonization and the development of otitis media in children. J Infect Dis. 1997;175:1440-1445.

20. Greene JC, Vermillion JR. The simplified oral hygiene index. J Am Dent Assoc. 1964; 68:7-13.

21. Silness J, Löe H. Periodontal disease in pregnancy. II. Correlation between oral hygiene and periodontal condition. Acta Odontol Scand. 1964;22:121-135.

22. Pearson WR, Lipman DJ. Improved tools for biological sequence comparison. Proc Natl Acad Sci U S A. 1988;85:2444-2448. 
23. Brook I. The role of anaerobic bacteria in chronic suppurative otitis media in children: implications for medical therapy. Anaerobe. 2008;14:297-300.

24. Litterio M, Hernandez C, Bernaldez P, Fiorill IG, Rubeglio E. Bacteroides fragilis group in middle ear infections. Anaerobe. 1999;5:359-362.

25. Könönen E, Kanervo A, Bryk A, Asikainen S, Jousimies-Somer H. Establishment of oral anaerobes during the first year of life. J Dent Res. 1999;78:1634-1639.

26. Kolenbrander PE. Oral microbial communities: biofilms, interactions, and genetic systems. Annu Rev Microbiol. 2000; 54:413-437.

27. Könönen E, Kanervo A, Salminen $K$, Jousimies-Somer $H$. $\beta$-Lactamase production and antimicrobial susceptibility of oral heterogeneous Fusobacterium nucleatum populations in young children. Antimicrob Agents Chemother. 1999;43:1270-1273.

28. Haraldsson G, Holbrook WP, Könönen E. Clonal persistence of oral Fusobacterium nucleatum in infancy. J Dent Res. 2004;83:500-504.

29. George KS, Reynolds MA, Falkler WA. Arbitrarily primed polymerase chain reaction fingerprinting and clonal analysis of oral Fusobacterium nucleatum isolates. Oral Microbiol Immunol. 1997;12:219-226

30. Thurnheer T, Guggenheim B, Gruica B, Gmür R. Infinite serovar and ribotype heterogeneity among oral Fusobacterium nucleatum strains? Anaerobe. 1999;5:79-92. 